\title{
Research of flat plate solar air collector in drying
}

\author{
Qiao $\mathrm{Xi}^{1}$, Weifan Long $^{1}$, and Qingsong $\mathrm{Ma}^{1, *}$ \\ ${ }^{1}$ Qingdao University of Technology, College of Architecture and Urban Planning, Qingdao, Shandong, China
}

\begin{abstract}
Solar drying technology has been widely used in engineering fields such us chemical drying because of its low cost and low pollution advantages. In this review, the structural forms, materials and coatings of the heat-absorbing panels of flat plate solar air collector are classified, and the experimental and theoretical results of the performance level of the solar air flat panel collector are summarized. In indoor tests, the energy efficiency of flat plate solar air collector is $30 \%$ to $79 \%$, and the energy efficiency of flat plate solar air collector in drying applications is $28 \%$ to $62 \%$.
\end{abstract}

\section{Introduction}

As early as 1881, Americans designed and trial-produced the first patented solar air collector. Today, solar air collectors have a history of 140 years. Because of its simple structure, low cost and convenient maintenance, it is widely used in heating, air conditioning, chemical drying and other fields. Drying is one of the first areas where people use solar energy. Solar drying methods have also developed from the initial natural drying to indirect drying, solar heat storage drying, and combined drying with various auxiliary equipment. At present, there are two methods of solar drying: one is to add a transparent cover for direct exposure, called absorption; the other is to use solar energy to heat a certain fluid, and then this fluid directly or indirectly heats the object to be dried, which is called indirect or convection. Various solar drying systems can be used for the processing of marine and agricultural products. In view of the fact that the solar collector is an indirect drying device, the drying efficiency can be improved by improving the performance level of the solar collector.

In this review, we conducted an energy analysis of various performance flat-plate air collectors based on indoor tests. We mainly studied and discussed the heat collection efficiency of flat plate solar air collector that greatly increases the heat transfer area due to the existence of fin absorbers, corrugated surfaces and porous media. It also introduces the application of solar air flat panel collectors in drying, as well as suggestions and future research trends on the application of solar collectors in the field of drying.

\section{Types of solar air collectors}

Solar air collectors are divided into flat solar air collectors and glass vacuum tube solar air collectors. The so-called "flat plate type" means "the area where the heat collector absorbs solar radiant energy is equal to the daylight area of the heat collector". The flat-plate solar air collector is mainly composed of a transparent cover plate, a heat absorption plate, an insulating layer, etc. It has the characteristics of simple structure, reliable operation, suitable cost, and large heat absorption area, making it the best choice for the chemical drying field. One of the types. The commonly used flat-plate solar air collectors are shown in the figure.
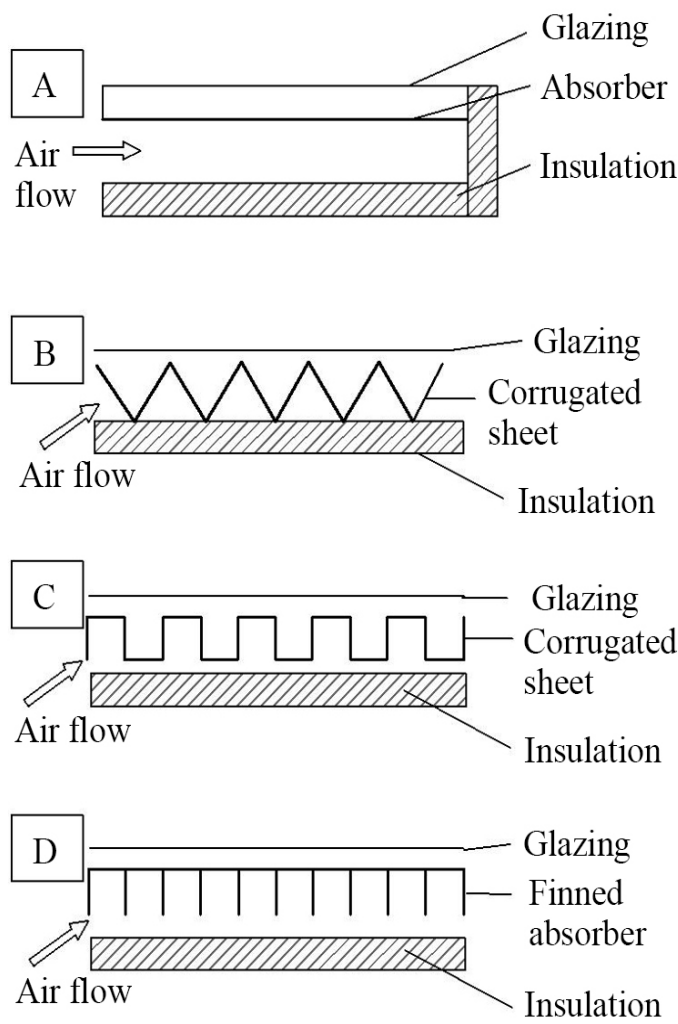

* Corresponding author: maqingsong@qut.edu.cn 


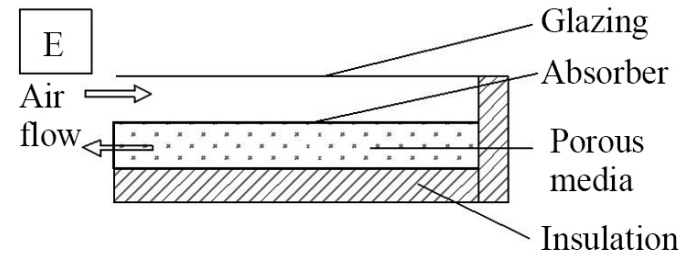

Fig. 1. Various types of air-plant solar collector.[1]

\section{Performance analysis of flat panel solar air collector}

Energy analysis is a traditional method used to evaluate the energy transfer and conversion process in flat plate solar air collector. The heat-absorbing plate is an important component in flat plate solar air collector that absorbs solar radiation energy and transfers heat to the heat transfer medium, and it is basically a flat-plate shape. By changing the structure, material, and coating of the heat-absorbing plate, the heat collection efficiency of the collector can be effectively changed, so as to classify the energy analysis research.

\subsection{Heat-absorbing plate structure}

Predecessors have modified the structure of the heatabsorbing plate in many ways to increase the heat collection efficiency by increasing convective heat transfer or increasing the amount of solar radiation energy absorbed. EI-sawi et al. [2] applied herringbone metal heat-absorbing panels obtained through continuous folding technology to solar air collectors and compared them with flat panels and V-groove panels. The results show that the herringbone heat-absorbing plate can be used under certain working conditions, the lower heat collection efficiency can be increased by $20 \%$, and the outlet temperature can be increased by $10 \%$. Mahboub and Moummi. [3] studied the energy analysis of a singleglass $60^{\circ}$ vee corrugated solar collector. The iterative method is used to predict the top heat loss and the temperature of the glass cover, and the results of the top surface heat loss coefficient calculated by the model are compared. They found that the results obtained are very consistent across the entire range of observation parameters. Kabeel et al. [4] studied the heat collection performance of single-pass FPC, finned, and vcorrugated solar air collectors under prevailing weather conditions in Egypt, and compared the air temperature difference and thermal efficiency between the three. They concluded that the v-corrugated collector was the most efficient, followed by the finned plate. The thermal efficiency of the v-corrugated solar air collector is 6$10.5 \%$ and $8-14.5 \%$ higher than that of the finned and flat plate solar collector, respectively. Karim and Hawlader [5] compared the thermal efficiency of vcorrugated collectors, finned air collectors and FPC collectors under the climatic conditions of Singapore. They found that compared with FPC, the thermal efficiency of the v-corrugated collector is higher, the efficiency of the single pass $\mathrm{v}$-corrugated collector is increased by $10-15 \%$, and the efficiency of the double pass v-shaped corrugated collector is increased by 5 $11 \%$. The double pass makes the collector more efficient than the single pass. And the thermal efficiency of the three collectors all increase with the increase of the flow rate. [6] Dovic and Andrassy studied various mathematical models of flat-plate and corrugated collectors, and explored the possibility of improving the thermal efficiency of flat-plate solar collectors. They used Fluent software to perform computer fluid dynamic (CFD) calculations on the heat exchange between the flat plate collectors with and without tubes. They concluded that under the same operating parameters and geometric structure, the heat collection efficiency of the glass tube collector is higher than that of the tube collector.

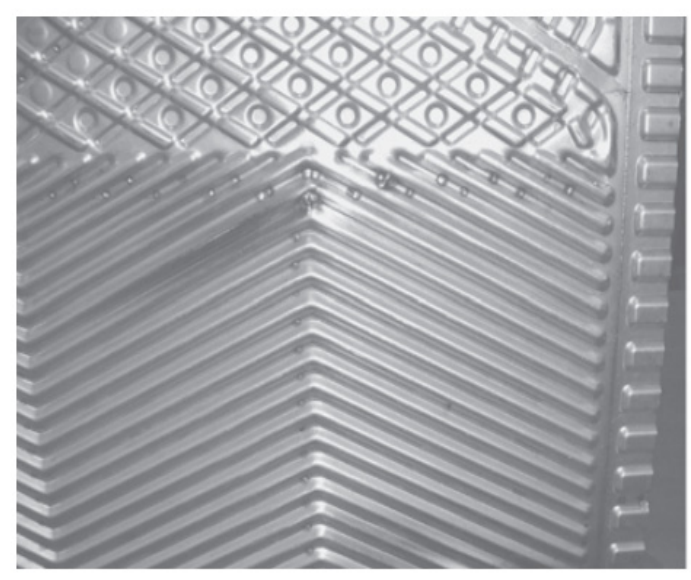

Fig. 2. Various types of air-plant solar collector. [6]

\subsection{Heat-absorbing plate materials}

Sopian et al. [7] established a theoretical model of double-pass solar collector containing non-steady porous media. By introducing steel wool in the second channel to increase the heat transfer area, the thermal efficiency of DPSC containing steel wool was evaluated to be about $60-70 \%$, with higher thermal performance. Layek et al. [8] studied a theoretical model for predicting the entropy production of a solar collector with a rough absorber plate with chamfered ribs and grooves, using conventional calculation procedures for absorbing irradiation and heat losses. The results show that the ability of the chamfered rib-groove roughened absorber plate to reduce irreversibility depends on the working state of the thermo-fluid, cs and temperature rise parameter. As the relative roughness height increases, the entropy production decreases. In addition, Layek et al. In the case of a set of relative groove positions of 0.4 , a relative roughness pitch of 6 and a chamfer angle of $181^{\circ}$, it shows that the entropy production is the smallest. Kabeel et al. [9] used phase change material (PCM) as thermal energy storage material to study the thermal performance parameters of a v-corrugated solar collector and FPC. The experimental results show that the solar collector has the highest efficiency when the PCM is 
used in combination with the v-corrugated solar collector. At a mass flow rate of $0.062 \mathrm{~kg} / \mathrm{s}$, the daily efficiency of the v-corrugated solar collector using PCM was $12 \%$ higher than that of the corresponding collector without PCM. The daily efficiencies of the flat panel collector using the PCM and the flat panel not using the PCM was $15 \%$ and $21.3 \%$ higher than the corresponding values, respectively.

\subsection{Heat absorbing plate coatings}

The coating material that converts solar energy into heat energy on the collector body is mainly divided into nonselective absorption coating and selective absorption coating. The non-selective absorber will heat up without the heat sink, so there will be more heat loss, and if the absorber is selective, the loss is relatively small, and the difference in heat dissipation coefficient will be through the existence of the heat sink to be compensated, the heat sink will cool the absorber. Moummy et al. [10] studied non-selective absorbents and selective absorbents through experiments. They studied the performance of the two absorbents by determining the temperature curves of the air in the rectangular fin and the absorption plate, and their results found that in the presence of fin, the selectivity of the absorbent would not be significantly improved.

\section{Drying applications}

Banout et al. [11] studied the performance of a new type of Double-pass solar drier (DPSD) for drying $45 \mathrm{~kg}$ of fresh peppers. Within $32 \mathrm{~h}$, the moisture content (MC) of the pepper drops from $90 \%$ to $10 \%$, the efficiency of DPSD and a typical cabinet drier (CD) and traditional outdoor sun drying equipment They are $62 \%, 22 \%$ and $24 \%$, respectively. DPSD shows higher performance in all test efficiency. Banout and Ehl [121] studied the drying performance of DPSC on $40 \mathrm{~kg}$ bamboo shoots. Within 33 hours, DPSC reduced the MC of bamboo shoots from $96 \%$ to $16.6 \%$, and its total drying efficiency was higher than that of solar drier and traditional open-sun drying.

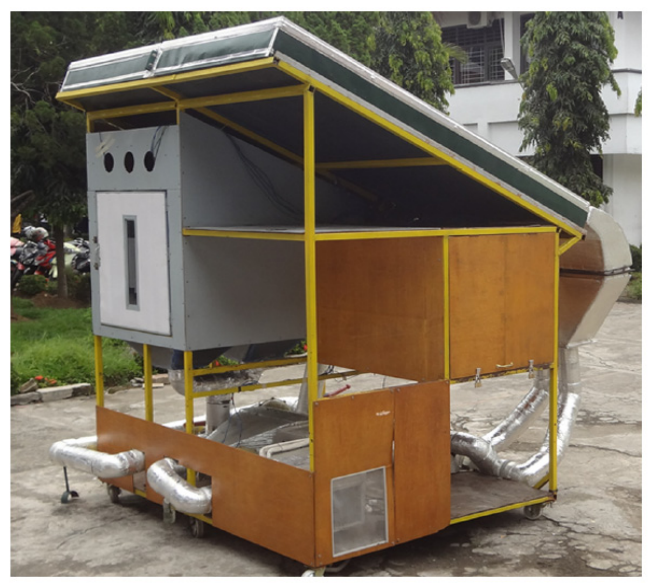

Fig. 3. Photograph of the solar-assisted heat pump dryer (SAHPD). [12]
Yahya et al. [12] studied the drying performance of a solar dryer (SD) and a solar-assisted heat pump dryer (SAHPD) on cassava chips, and analysed a fin type DPSC with integrated heat pump for drying $30.8 \mathrm{~kg}$ of cassava chips Under the conditions of an average temperature of $40^{\circ} \mathrm{C}$ to $45^{\circ} \mathrm{C}$ and a mass flow rate of $0.124 \mathrm{~kg} / \mathrm{s}$, the MC of cassava dropped from $61 \%$ to $10.5 \%$ within 13 hours. Yahya et al. [13] developed a solar drying system composed of a fluidized bed and a biomass furnace for drying $12 \mathrm{~kg}$ of rice. At the mass flow rate of $0.125 \mathrm{~kg} / \mathrm{s}$ and indoor temperatures of $61^{\circ} \mathrm{C}$ and $78^{\circ} \mathrm{C}$, the $\mathrm{MC}$ of rice dropped from $20 \%$ to $14 \%$ in 485 seconds. At $61^{\circ} \mathrm{C}$ and $78^{\circ} \mathrm{C}$, the average thermal efficiency is $13.45 \%$ and $16.28 \%$ respectively. Yahya et al. [14] evaluated the performance of a solar collector integrated with a fluidized bed for drying $12 \mathrm{~kg}$ of rice. Under the conditions of a temperature of $50^{\circ} \mathrm{C}$ and a relative humidity of $23 \%$, the $\mathrm{MC}$ of the rice was reduced from $20 \%$ to $14 \%$. The maximum drying rate can reach $0.04 \mathrm{~kg} / \mathrm{min}$.

Fudholi et al.[15] studied the performance of a reverse $\mathrm{V}$-groove collector for drying $24 \mathrm{~kg}$ chili. The MC of the chili dropped from $80 \%$ to $10 \%$ within 31 hours, which saved $49 \%$ time compared with open sun drying. Under a mass flow rate of $0.07 \mathrm{~kg} / \mathrm{s}$ and average solar radiation of $420 \mathrm{w} / \mathrm{m} 2$, the efficiencies of the collector, pick-up and drying system were $38 \%, 30 \%$ and 6\%, respectively. Mohanraj and Chandrasekar [16] evaluated the performance of solar collectors using gravel as heat storage materials for drying chili. Under the air flow rate of $0.25 \mathrm{~kg} / \mathrm{s}$, the MC of chili decreased from $73 \%$ to $9 \%$ within 24 hours, and the drying efficiency was $21 \%$. Yahya et al Studied the performance of a solar-assisted drying system consisting of a $13.8 \mathrm{~m}^{2} \mathrm{~V}$-groove collector for drying fresh tea. When the ambient temperature is between $27^{\circ} \mathrm{C}$ and $34^{\circ} \mathrm{C}$ and the average solar radiation level is $567.4 \mathrm{w} / \mathrm{m}^{2}$, the temperature in the drying chamber can reach $50^{\circ} \mathrm{C}$. The results showed that $10.03 \mathrm{~kg}$ green tea could be dried to $2.86 \mathrm{~kg}$ in 12 hours, and the MC of green tea decreased from $87 \%$ to $54 \%$.

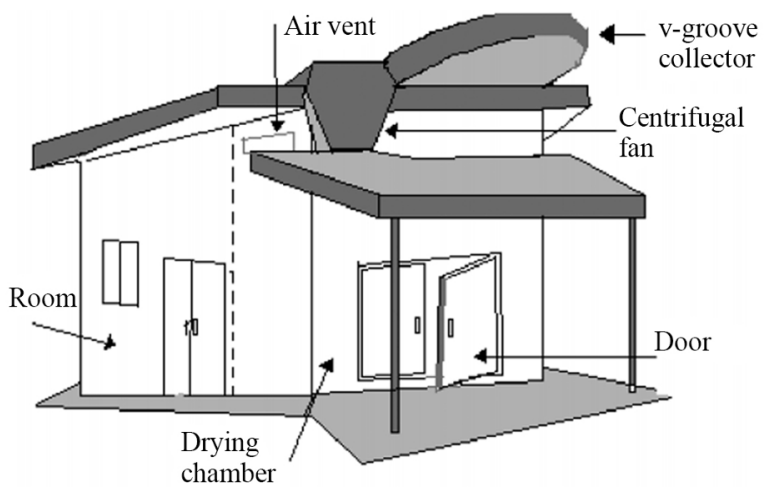

Fig. 4. The design of colar assisted drying system. [17]

Fudholi et al. [18] used energy and exergy analysis to evaluated a solar drier, which consists of solar panels with fins. Three different drying models were fitted by nonlinear regression method. The MC of seaweed 
decreased from $90 \%$ to $10 \%$ (WB) in 15 hours. When the average solar radiation is $500 \mathrm{~W} / \mathrm{m}^{2}$ and the air flow rate is $0.05 \mathrm{~kg} / \mathrm{s}$, the efficiency of drying system, pick-up and solar collection is $13 \%, 45 \%$ and $28 \%$ respectively.

\section{Discussion}

The exit temperature and thermal efficiency of FPC are usually low. The thermal efficiency can be improved by increasing the surface area of fin absorbers, corrugated surfaces, slat absorbers, folded plates, etc. In the DPSC, the filled bed increases the heat transfer rate and acts as a heat storage. For the study of expanding the heat transfer area in both theory and experiment of DPSC, the combination of filled bed has a more significant heat transfer rate, which is more favourable than increasing the artificial roughness and expanding the surface, and the heat storage effect is more obvious.

\section{Conclusion}

A solar collector is a simple device that generates heat from solar energy without using electricity and any conventional fuels (such as natural gas, coal, fuel wood and diesel). However, it can be combined with cabinet dryers, tunnel dryers, tray dryers, box dryers and fluidized beds operating on conventional fuels to save fuel consumption in these conventional dryers. Solar collectors can be used more efficiently for drying under controlled conditions. In general, flat plate solar collectors produce hot air at low to medium temperatures and have been found to be suitable for drying agricultural products. Several flat-plate solar air collectors for drying have been developed in different countries. Depending on the energy analysis, different technical performances of these collectors were obtained.

\section{Acknowledgments}

This research is supported by grants from the Natural Science Foundation of Shandong Province (No. ZR201910280141).

\section{References}

1. A. Fudholi and K. Sopian, Renewable and Sustainable Energy Reviews 102, 333-345 (2019)

2. EI-SawiAm, W. A. S and YounanMY, Applied Thermal Engineering 30(8/9), 864-871 (2010)

3. C. Mahboub and N. Moummi, Solar Energy 86, 804-808 (2012)

4. K. A. E., K. A., S. S. M. and Z. M. E., 138, (2016)

5. M. A. Karim and M. N. A. Hawlader, Energy 31, 452-470 (2006)

6. D. Dović and M. Andrassy, Solar Energy 86, 24162431 (2012)

7. K. Sopian, M. A. Alghoul, E. M. Alfegi, M. Y. Sulaiman and E. A. Musa, Renewable Energy 34, 640-645 (2009)

8. A. Layek, J. S. Saini and S. C. Solanki, Renewable Energy 32, 1967-1980 (2007)

9. A. E. Kabeel, A. Khalil, S. M. Shalaby and M. E. Zayed, Energy Conversion and Management 113, 264-272 (2016)

10. N. Moummi, S. Youcef-Ali, A. Moummi and J. Y. Desmons, Renewable Energy 29, 2053-2064 (2004)

11. J. Banout, P. Ehl, J. Havlik, B. Lojka, Z. Polesny and V. Verner, Solar Energy 85, 506-515 (2011)

12. M. Yahya, A. Fudholi, H. Hafizh and K. Sopian, Solar Energy 136, 606-613 (2016)

13. M. Yahya, A. Fudholi and K. Sopian, Renewable Energy 105, 22-29 (2017)

14. Y. M, F. A and S. K, Res J Appl Sci Eng Technol 12(4), 420-426 (2016)

15. F. A, R. MH, N. MF, A. MS, A. Z, O. MY and S. K, Ecosystem and Development, 132-137 (2012)

16. M. M and C. P, Eng Sci Technol 4(3), 305-314 (2009)

17. S. A. Eltief, M. H. Ruslan and B. Yatim, Desalination 209, 151-155 (2007)

18. A. Fudholi, K. Sopian, M. Y. Othman and M. H. Ruslan, Energy and Buildings 68, 121-129 (2014) 